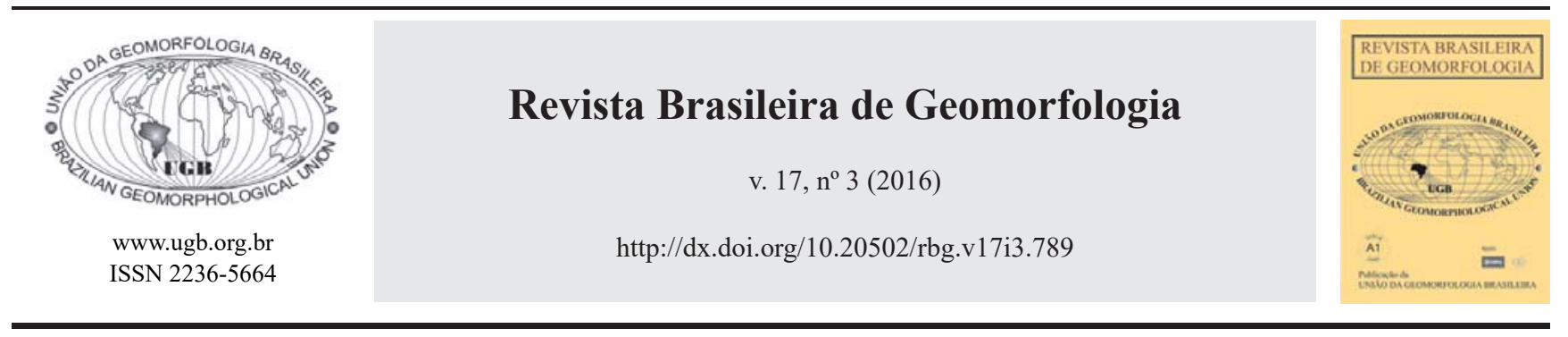

\title{
INFLUÊNCIA NEOTECTÔNICA NA MORFOLOGIA DO SISTEMA DE ILHAS BARREIRAS, NORDESTE DO BRASIL
}

\section{NEOTECTONIC INFLUENCE ON BARRIERS ISLANDS SYSTEM MORPHOLOGY, NORTHEAST BRAZIL}

\author{
Vítor Peixoto Lucas Rios \\ Departamento de Geologia, Universidade Federal do Rio Grande do Norte \\ Av. Senador salgado Filho, s/n, Natal, Rio Grande do Norte, CEP 59078-970, Brasil \\ Email: vitorpeixoto.geo@gmail.com
}

Venerando Eustáquio Amaro

Departamento de Geologia, Universidade Federal do Rio Grande do Norte Av. Senador salgado Filho, s/n, Natal, Rio Grande do Norte, CEP 59078-970, Brasil Email:amaro@geologia.ufrn.br

Marcela Marques Vieira

Departamento de Geologia, Universidade Federal do Rio Grande do Norte Av. Senador salgado Filho, s/n, Natal, Rio Grande do Norte, CEP 59078-970, Brasil Email: marcela@geologia.ufrn.br

Maria de Fátima Alves de Matos

Departamento de Geologia, Universidade Federal do Rio Grande do Norte Av. Senador salgado Filho, s/n, Natal, Rio Grande do Norte, CEP 59078-970, Brasil Email: mfatimaalves.m@gmail.com

Mattheus da Cunha Prudêncio

Departamento de Geologia, Universidade Federal do Rio Grande do Norte Av. Senador salgado Filho, s/n, Natal, Rio Grande do Norte, CEP 59078-970, Brasil

Email: mattheus.prudencio@hotmail.com

Michel Rodrigues Camara

Departamento de Geologia, Universidade Federal do Rio Grande do Norte Av. Senador salgado Filho, s/n, Natal, Rio Grande do Norte, CEP 59078-970, Brasil

Email: rodcam1987@gmail.com

\section{Informações sobre o Artigo}

Recebido (Received): 05/07/2015

Aceito (Accepted): $27 / 02 / 2016$

\section{Resumo:}

Visando o entendimento global da atuação dos eventos neotectônicos ao longo do Cenozoico costeiro o presente estudo integra o conhecimento acerca dos registros geológicos de subsuperfície por meio da amostragem vibracorer com a análise dos lineamentos morfoestruturais da Província Costeira através do processamento digital de imagens de satélites. A amostragem vibracorer tem 


\section{Palavras-chave:}

Reativação Tectônica; Ilhas Barreiras; Vibracore;

Processamento Digital de

Imagens; Lineamentos

Morfoestruturais.

\section{Keywords:}

Tectonic Reactivation;

Barrier Islands; Vibracore;

Digital Image Processing;

Morphostructural Lineaments.

sido relevante no estudo dos depósitos sedimentares costeiros, pois permite a descrição faciológica do substrato sedimentar a baixo custo. Somado a isto, o processamento digital de imagens radiográficas dos vibracores trouxe uma visão sinóptica, rápida e eficiente na descrição das sequências sedimentares. Este estudo foi realizado nos depósitos sedimentares holocênicos do sistema de ilhas barreiras característico do litoral setentrional do Estado do Rio Grande do Norte (RN), Nordeste do Brasil. Este ambiente é extremamente suscetível a processos morfodinâmicos e intensamente afetado pelas condições hidrodinâmicas como a deriva litorânea, os ventos alísios, o clima de ondas, e o regime de mesomarés. Estas condições ambientais estão instaladas numa zona do litoral marcada pela reativação de estruturas antigas do Sistema de Falhas de Carnaubais (NE) e Afonso Bezerra (NW). O estudo realizou a análise sedimentar físico-química dos vibracores associada a técnicas de processamento digital de imagens radiográficas. Quatro fácies sedimentares foram reconhecidas: Areia Siliciclástica com Grânulos e Cascalhos, Areia Siliciclástica, Lama Terrígena e Marga Arenosa. Os vibracores foram integrados em um perfil geológico esquemático no qual foi possível identificar a intercalação de fácies lamosas (Intertidal Flat) e fácies arenosas (Tidal Inlet), que demonstra a intensa dinâmica costeira característica da região, associada à movimentação tectônica recente, indicando que a abertura e o fechamento dos canais de maré ocorrem geralmente em curto espaço de tempo, acompanhando as descontinuidades estruturais. A integração da amostragem em subsuperfície com perfis litofaciológicos esquemáticos, geofísicos e com a análise da geometria do sistema de ilhas barreiras baseada na interpretação dos lineamentos estruturais, possibilitou também correlacionar os efeitos da neotectônica nas mudanças da geometria e morfologia costeira, reconhecendo a influência do controle tectônico da reativação do Sistema de Falhas de Carnaubais e Afonso Bezerra na direção da abertura dos canais de maré.

\begin{abstract}
:
Aiming the global understanding of neotectonic events performance along coastal Cenozoic, this study integrate geological subsurface records by vibracorer with morphostructural lineaments analyses of Coast Province by digital processing of satellite images. Description of coastal sedimentary deposits by vibracorer drilling technic has been relevant, since it allows the facies sedimentary description of the substrate at low cost. Besides, digital processing techniques of vibracore radiographic images have brought a synoptic, fast and resourceful view for description of these sedimentary deposits. This article was developed in holocenic sedimentary deposits of a barrier island and sand spits system, typical of northern coast of Rio Grande do Norte State, Northeast Brazil. This environment is highly susceptible to erosional/depositional processes and strongly affected by wind regime, hydrodynamic and by reactivation of early structures. It is installed on a coastal zone marked by the reactivation of preterit structures of the Carnaubais and Afonso Bezerra Fault System. This study applied chemical and physical sedimentary analysis associated with digital processing techniques of radiographic images. This allowed recognizing four distinct sedimentary facies: Sand Siliciclastic with Granule and Gravels, Sand Siliciclastic, Terrigenous Mud and Sandy Marl. The analysis and interpretation of vibrocores endorsed to identify muddy facies (describing Intertidal Flat subfacies) and sandy facies (describing Tidal Inlet subfacies) interbeds, that highlight the intense coastal dynamic which the region is subjected, suggesting that the opening and closing of tidal channels occur in short time interval (range of years) and preferably in situations prior geological structural discontinuity. Thus, integration of vibracorer sampling with analysis of geophysical and lithological sections, and geometry of barriers islands system through mapping structural lineaments, allowed correlating the effects of neotectonic changes of coastal morphology and geometry, recognizing the influence of tectonic control of the Carnaubais and Afonso Bezerra Fault System reactivation and the direction of tidal channel aperture.
\end{abstract}




\section{Introdução}

Os estudos sobre as atividades neotectônicas como condicionante controladora da morfologia costeira ainda é um tema recente e, juntamente com os agentes climatológicos, são considerados os fatores mais importantes que controlam a morfologia e sedimentação nas margens passivas, sendo complexo definir a contribuição de cada um destes isoladamente (BEZERRA et al., 2008). Entretanto, um crescente número de trabalhos tem mostrado que as unidades pós-rifte, incluindo aquelas de idade cenozoica, sofreram deformação tectônica e influenciam diretamente a morfologia das bacias e a sedimentação recente (BEZERRA, 2011). Assim o principal objetivo deste trabalho é demonstrar a real influência das atividades neotectônicas no desenvolvimento da morfologia costeira atual do litoral setentrional do Rio Grande do Norte (RN).

A aplicação de métodos de análise morfotectônica tem se revelado útil como suporte aos estudos de áreas sujeitas a abalos sísmicos como, por exemplo, no Japão e na costa oeste dos Estados Unidos, ou mesmo no município de Pedra Preta-RN (DANTAS et al., 2011), associados aos riscos geológicos e implicações com relação à construção de edificações ou grandes obras de engenharia (FONSECA, 2006). Em áreas antigas de mineração, a deformação neotectônica pode se tornar um problema de segurança ao desenvolvimento da atividade (FUCHS \& MULLER, 2001). Em bacias petrolíferas maduras, tais análises têm se mostrado muito adequadas à descoberta de novas ocorrências e à otimização na recuperação do petróleo (LIMA, 1999).

Mundialmente, os estudos sobre o tectonismo intraplaca nas margens passivas têm indicado soerguimento e subsidência dos depósitos sedimentares em escala local, contudo não sendo aplicáveis integralmente a toda a margem. Na margem passiva da Escandinávia, por exemplo, a elevação pós-rifte afeta diferentemente cada lado da margem, onde a elevação Plio-Pleistoceno ocorre apenas no sul da Noruega e produz taxas de rebaixamento distintas no desenvolvimento das bacias sedimentares (RIIS, 1996). Na margem da Antártica, a datação de apatitas pelo método dos traços de fissão indicou uma história de resfriamento distinta dos blocos tectônicos, influenciada pela diferença da denudação regional (LISKER, 2002). No oeste da Groelândia, Japsen et al. (2006) propôs que o soerguimento dos flancos rifte para a elevação atual (pós-rifte) ocorreu principalmente no Cenozoico e que, segundo Bonow et al. (2006) foi heterogênea e provocou o basculamento das paleosuperfícies do Mesozoico e Cenozoico, cujas inclinações obedecem preferencialmente aos principais blocos estruturalmente controlados, correspondendo os limites entre estes blocos às escarpas e quebras de relevo associadas à reativação das falhas, como também observado por Bezerra et al., (2008).

O relevo norte-riograndense, no nordeste do Brasil, denota a complexidade dos processos precursores da ruptura do Gondwana e subsequente evolução do Atlântico Sul. Após a completa separação entre as placas Sul-americana e Africana no Cenozoico, a Bacia Potiguar foi marcada pela reativação dos sistemas conjugados de falhas Carnaubais (NE) e Afonso Bezerra (NW), que compartimentam o litoral setentrional do $\mathrm{RN}$ e correspondem à principal estrutura que controla a sedimentação na bacia e a deposição dos sedimentos costeiros na região (FONSECA, 1996; VITAL et al., 2003). A evolução do litoral setentrional do RN está intimamente relacionada aos movimentos verticais resultantes das atividades tectônicas e da reativação desse sistema de falhas (SRIVASTAVA \& CORSINO, 1984), que exercem controle sobre a sedimentação dos depósitos holocênicos e sobre o padrão de drenagens (BEZERRA, 1999; MOURA-LIMA et al., 2010). Estes sistemas deposicionais costeiros apresentam-se como importantes elementos de estudo, visto que reativações tectônicas recentes influenciam a dinâmica costeira, assim como provocam reativações no arcabouço estrutural da Bacia Potiguar, permitindo a migração e o armazenamento de petróleo na parte rasa da bacia, a aproximadamente 500 metros de profundidade (DANTAS, 1998).

Na Bacia Potiguar, o Neógeno-Quaternário é dominado por compressão horizontal máxima E-W, oblíqua às direções estruturais NE e NW do sistema de falhas de Carnaubais e Afonso Bezerra. Este campo de tensões favorece compressão de estruturas transcorrentes dextrais e sinistrais. O resultado morfológico são estruturas topográficas na forma de domos e arqueamentos como, por exemplo, em Mangue Seco, Serra do Mel e Alto de Macau (BEZERRA, 2011).

\section{Contexto Geológico}

A área de estudo está inserida no município de Macau-RN, precisamente no chamado estuário de Diogo 
Lopes, caracterizado por um sistema de ilhas barreiras e esporões arenosos sujeitados a intensa ação da dinâmica costeira, em que forçantes hidrodinâmicas, eólicas e o arranjo estrutural prévio originam a alta instabilidade das feições morfológicas, evidenciada nas constantes modificações da linha de costa em curtos períodos de tempo (FERREIRA et al., 2014; SANTOS et al., 2014; AMARO et al., 2013; SANTOS \& AMARO, 2013). A modificação da morfologia costeira sofre ainda com a interferência antrópica, como as atividades das indústrias petrolífera, salineira, carcinicultura e parques eólicos que correspondem a atividades socioeconômicas de grande relevância para o RN.

O contexto geológico no qual se insere a área de estudo é o da Bacia Potiguar. O arcabouço geológico é composto por unidades litológicas do Terciário ao Quaternário, dispostas estratigraficamente da base para o topo em: Formação Tibau, Formação Barreiras e Formação Potengi. A zona costeira constitui-se por sedimentos provenientes dos processos deposicionais contemporâneos, caracterizados como depósitos do
Holoceno (aluvional, eólico e marinho), que recobrem as unidades mais antigas ao longo da costa (SILVA \& NOGUEIRA, 1995; FARIAS, 1997; STATTEGGER et al., 2006). A diversidade desses depósitos abrange os tipos eólicos vegetados e não vegetados, de praia, de intermaré e de supramaré. Na compartimentação de relevo identificam-se as seguintes feições geomorfológicas (Figura_1): dunas fixas, dunas móveis, depressões interdunares, falésias, planície flúvio-estuarina, planície de maré, barras arenosas e ilhas barreiras (RIOS \& AMARO, 2012).

\section{Materiais e Métodos}

Estudos morfodinâmicos envolvem a integração dos elementos geomórficos, tectônicos (pretéritos e atuais) e dos registros lito e aloestratigráficos (FONSECA, 2006). No RN o conhecimento que se refere aos registros e à morfologia costeira ainda carece de maior contribuição estrutural sistemática. A complexidade geoambiental da área foi estudada a partir da integração

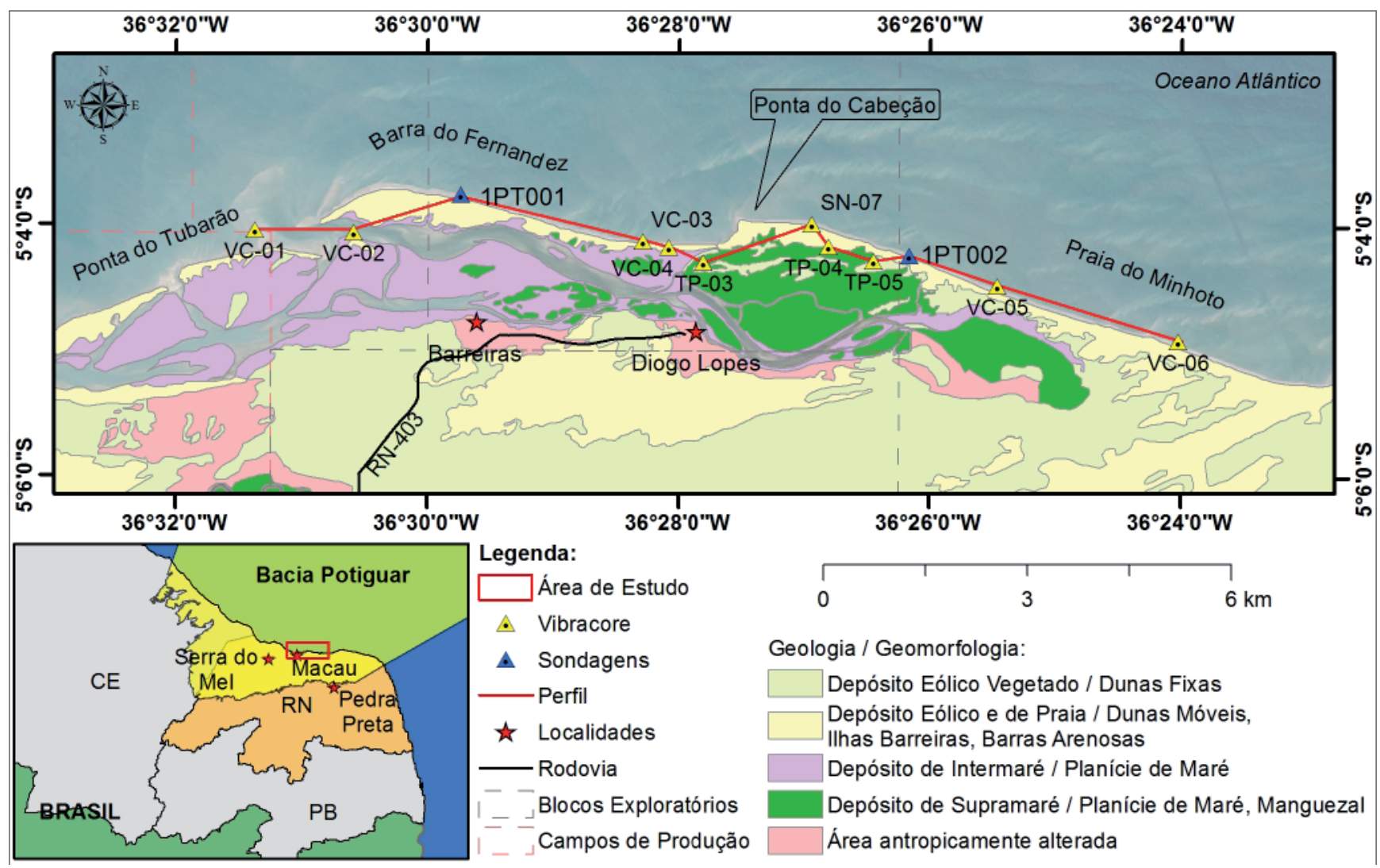

Figura 1 - Mapa geológico-geomorfológico da área de estudo sobreposto à imagem do satélite Landsat 8 - OLI (Operational Land Imager) com composição RGB (Red-Green-Blue) 2-1-5. Desde a aquisição dos vibracorer em 2012, a Ilha da Ponta do Tubarão migrou para oeste e se subdividiu em duas partes no ano de 2015. Assim, o que era um banco lamoso aflorante na linha de costa (onde foi perfurado o vibracore VC-01) atualmente é caracterizado por um canal de maré. 
de várias metodologias com ênfase à análise morfotectônica, que permitiu estabelecer um quadro mais coerente quanto à disposição dos sedimentos costeiros.

\section{Testemunhagem por Vibracorer}

O emprego da amostragem por vibracorer permite a coleta de sedimentos recentes em subsuperfície e tem sido relevante no estudo de sequências sedimentares inconsolidadas ou subconsolidadas. Nove vibracores foram extraídos ao longo da linha de costa (Figura_1) com recuperação de até dois metros de profundidade, dos quais dois foram amostrados na ilha barreira de Ponta do Tubarão (VC-01 e VC-02); mais dois na barra arenosa do Fernandez (VC-03 e VC-04); outros dois após a Ponta do Cabeção até próximo à Praia do Minhoto (VC-05 e VC-06); e três na paleoilha dos Cavalos (TP-03, TP-04 e TP-05) (RIOS \& AMARO, 2012 e PALHANO, 2013). Como referência geodésica para o levantamento, considerou-se a maré baixa de quadratura ao longo da linha de costa e as estações geodésicas de monitoramento estabelecidas na área de estudo pela Rede GNSS (Global Navigation Satellite System) do Litoral Setentrional do RN, estabelecida por Santos \& Amaro (2011), para controle de posicionamentos geodésicos e altitudes ortométricas com precisão decimétrica em relação ao Sistema Geodésico Brasileiro (SGB). Desta forma, foi possível manter a mesma altimetria para o topo dos furos inseridos no banco lamoso (paleomangue) que afloram nas proximidades da linha de praia. O vibracore $\mathrm{SN}-07$ e as sondagens 1PT001 e 1PT002 levantados por Santos Neto (2007) e Nascimento (2009) respectivamente fazem parte do banco de dados de amostragem de subsuperfície e foram utilizados para integrar a seção litofaciológica da região, apresentada na Figura_8.

\section{Análise Sedimentológica}

No total foram analisadas 60 amostras dos nove vibracores coletados neste sistema de ilhas barreiras. Inicialmente efetuou-se a remoção dos sais (duas ou mais lavagens), com posterior secagem a uma temperatura $\leq 60^{\circ} \mathrm{C}$, conforme Lima et al. (2002) e pesagem das amostras (aproximadamente $100 \mathrm{~g}$ ). Em seguida, as amostras foram submetidas ao peneiramento a $2,0 \mathrm{~mm}$, onde a fração $>2,0 \mathrm{~mm}$ correspondente aos bioclastos foi pesada, descrita e armazenada para posterior análise geocronológica. O restante da amostra, denominada de fração resultante, foi quarteada e analisada no aspecto químico e granulométrico.

A análise química consistiu na determinação do teor de carbonato e de matéria orgânica (MO). O teor de carbonato foi determinado a partir do tratamento das amostras com ácido clorídrico $(\mathrm{HCl})$, diluído a $10 \%$, sobre cerca de $30 \mathrm{~g}$ da fração resultante. Enquanto o teor de MO consistiu no tratamento da amostra, pós-tratamento do carbonato, com peróxido de hidrogênio $\left(\mathrm{H}_{2} \mathrm{O}_{2}\right)$ diluído a $50 \%$.

Após eliminação do carbonato e da matéria orgânica as amostras foram submetidas à análise granulométrica. A fração $>2,0 \mathrm{~mm}$ foi analisada por peneiramento convencional, enquanto que a fração $<2,0 \mathrm{~mm}$ foi analisada no granulômetro a laser (CILAS 1180) que determina a fração granulométrica do material no intervalo de 2,0 a 0,02 mm, e é programado para fornecer os dados a cada $1 / 2$ phi na forma de planilhas e histogramas do diâmetro das partículas e valores cumulativos (RIOS \& AMARO, 2012).

\section{Processamento Digital das Imagens Radiográficas dos Testemunhos Vibracorer}

As radiografias foram realizadas no Hospital Universitário Onofre Lopes da Universidade Federal do Rio Grande do Norte, com o auxílio de profissionais especializados na área de Radiologia.

Com o intuito de realçar as finas estruturas sedimentares internas características dos depósitos lagunares areno-lamosos, para melhor identificação das variações granulométricas, estruturas sedimentares e bioclastos aprisionados nos sedimentos coletados, os negativos foram digitalizados e submetidos ao tratamento digital de imagens (RODRIGUES, 2014), utilizando técnicas de ajustes de contraste, brilho, matiz, saturação, composição no sistema de cores híbrido RGBI (Red-Green-Blue-Intensity) e filtragens digitais. A técnica baseou-se na utilização de filtros direcionais, filtros de realce e contraste por manipulação dos histogramas em diferentes composições coloridas. A interpretação visual considerou o arranjo espacial das propriedades físicas e químicas dos alvos naturais nas radiografias e a análise da textura, forma, tonalidades, cores e tamanho do pixel. 


\section{Processamento Digital das Imagens de Satélites}

Os dados de sensoriamento remoto utilizados corresponderam a imagens obtidas por sensores orbitais ópticos do Landsat 8 - OLI (Operational Land Imager) produzidas pela National Aeronautics and Space Administration (NASA), datadas de 23 de agosto de 2014 (USGS), as quais foram tratadas por meio de técnicas de Processamento Digital de Imagens (PDI), que possibilitaram o realce das características de interesse, destacando as unidades geológicas, geomorfológicas e estruturais. As técnicas de PDI envolveram realce por decorrelação de bandas espectrais, Análise por Principais Componentes (APC), composições coloridas nos sistemas de cores Red-Green-Blue (RGB) e Hue-Saturation-Intensity (HSI), composições híbridas, aplicação de filtragem direcional no canal Intensity, razão entre bandas espectrais, métodos de índices (Normalized Difference Vegetation Index - NDVI; Normalized Difference Water Index - NDWI) e o realce por manipulação dos histogramas. Assim, foi possível analisar e interpretar os dados contidos nas imagens, identificando as unidades geológicas e geormorfológicas e os lineamentos estruturais, fundamentais na avaliação dos alvos geológicos e nos mapeamentos realizados.

A plataforma Landsat 8 opera com dois instrumentos imageadores: Operational Land Imager (OLI) e Thermal Infrared Sensor (TIRS). Os produtos OLI, utilizados neste trabalho, consistem de nove bandas multiespectrais com resolução espacial de 30 metros (bandas de 1 a 7 e 9), das quais a banda 1 (com comprimento de onda entre $0,43-0,45 \mu \mathrm{m}$ ), denominada Costeira (Coastal), é útil para estudos costeiros; as bandas $2(0,45-0,51 \mu \mathrm{m}), 3(0,53-0,59 \mu \mathrm{m})$ e $4(0,64-0,67$ $\mu \mathrm{m})$, com seus respectivos comprimentos de onda, se situam na faixa do visível do espectro eletromagnético correspondentes respectivamente às cores Azul (Blue), Verde (Green) e Vermelho (Red); as bandas $5(0,85-0,88$ $\mu \mathrm{m}), 6(1,57-1,65 \mu \mathrm{m})$ e $7(2,11-2,29 \mu \mathrm{m})$ correspondem respectivamente ao infravermelho próximo (Near Infrared - NIR) e aos infravermelhos de ondas curtas (Shortwave Infrared - SWIR 1 e 2); a banda 9 ou Cirrus (1,36-1,38 $\mu \mathrm{m})$ é utilizada para a detecção de nuvens; e a banda $8(0,50-0,68 \mu \mathrm{m})$ é a pancromática, com resolução espacial de 15 metros. As faixas térmicas do instrumento TIRS são úteis no fornecimento de temperaturas de superfície mais precisas e os dados são coletados no pixel de 100 metros (USGS, 2015).

\section{Resultados}

\section{Análise Sedimentológica}

Os parâmetros estatísticos, oriundos das análises granulométricas, permitiram classificar os sedimentos de acordo com a média granulométrica ou diâmetro médio dos grãos segundo Udden (1914) e Wentworth (1922), e texturalmente segundo Folk \& Ward (1957). As análises composicionais, quantificação de carbonato e matéria orgânica, combinadas às análises granulométricas permitiram classificar os sedimentos segundo Folk (1954), Shepard (1954) e Larsonneur (1977) modificado por Dias (1996), Freire et al. (1997) e Vital et al. (2006). Assim, foram identificadas quatro fácies sedimentológicas nas amostras analisadas, tais quais: Areia Siliciclástica com Grânulos e Cascalhos (AS1a), Areia Siliciclástica (AS1b), Lama Terrígena (LL1) e Marga Arenosa (LL2), como mostra resumidamente a Tabela_1.

A fácies Areia Siliciclástica com Grânulos e Cascalhos (AS1a) apresenta sedimentos cuja granulometria varia de média a grossa, onde os grãos são moderadamente a pobremente selecionados e variam de angulosos a subarredondados. Os teores de carbonato e matéria orgânica variam de 3 a $22 \%$, e de 0 a $3 \%$ respectivamente. Enquanto para a fácies Areia Siliciclástica (AS1b), os sedimentos constituintes apresentam granulometria variando de muito fina a média, os grãos são moderadamente a pobremente selecionados, variando de subangulosos a arredondados. Os teores de carbonato e matéria orgânica variam de 0 a $15 \%$, e de 0 a $4 \%$ respectivamente. A associação das fácies AS1b para AS1a, seja em granodecrescência ascendente (fining upward, ASla sotoposta) ou em granocrescência ascendente (coarsening upward, ASla sobrejacente), é peculiar da subfácies de Canais de Maré (Tidal Inlet) (SILVA, 1991) indicando, assim, a migração e reocupação desses canais de maré (Tabela_2).

As fácies Lama Terrígena (LL1) e Marga Arenosa (LL2) afloram como bancos lamosos ou paleomangues na linha de costa, ao longo do trecho de estudo. Ocorrem geralmente sobrepostas e/ou intercaladas às fácies arenosas de Areia Siliciclástica com Grânulos e Cascalhos (AS1a) e Areia Siliciclástica (AS1b). A fácies Lama Terrígena (LL1) mostram sedimentos de granulometria silte, e os grãos variam de muito pobremente a pobremente selecionados. Os teores de carbonato e matéria orgânica variam de 2 a $29 \%$, e de 1 a $14 \%$ respectivamente. A fácies Marga Arenosa (LL2) é também 
Tabela 1: Tabela de Classificação Sedimentar com destaque para as fácies identificadas nesse estudo.

\begin{tabular}{|c|c|c|c|c|}
\hline \multirow{2}{*}{$\begin{array}{c}\text { Subdivisões Princi- } \\
\text { pais }\end{array}$} & \multirow{2}{*}{$\begin{array}{c}\text { Seixos, Grânu- } \\
\text { los, Conquinas } \\
\text { ou Rodólitos } \\
\text { (Lama < 15\%; } \\
\text { Md > 2,0 mm) }\end{array}$} & \multicolumn{2}{|c|}{$\begin{array}{c}\text { Lama }<15 \% \text {; Areia + Lama }>50 \% \\
\text { Md }<2,0 \mathrm{~mm}\end{array}$} & \multirow{2}{*}{$\begin{array}{c}\text { Sedimentos } \\
\text { Lamosos } \\
(\text { Lama }> \\
15 \%)\end{array}$} \\
\hline & & $\begin{array}{c}15 \%<\text { Superior a } 2,0 \\
\text { mm }<50 \%\end{array}$ & $\begin{array}{c}\text { Superior a } 2,0 \\
\mathrm{~mm}<\mathbf{5 0} \%\end{array}$ & \\
\hline $\begin{array}{c}\text { Sedimentos Siliciclás- } \\
\text { ticos (Carbonato }< \\
30 \%) \\
\end{array}$ & $\begin{array}{l}\text { Cascalho Silici- } \\
\text { clástico CL1 }\end{array}$ & $\begin{array}{r}\text { Grânulos e } \\
\text { As }\end{array}$ & $\begin{array}{l}\text { Areia Siliciclás- } \\
\text { tica AS1b }\end{array}$ & $\begin{array}{l}\text { Lama Terrí- } \\
\text { gena LL1 }\end{array}$ \\
\hline $\begin{array}{c}\text { Sedimentos Silici-Bio- } \\
\text { clásticos (Carbonato = } \\
30 \% \text { a } 50 \%)\end{array}$ & $\begin{array}{l}\text { Cascalho Silici- } \\
\text { Bioclástico CL2 }\end{array}$ & $\begin{array}{r}\text { Areia Silici-1 } \\
\text { com Grânulc } \\
\text { lhos A }\end{array}$ & $\begin{array}{r}\text { Areic } \\
\text { Bioc } \\
\text { A }\end{array}$ & $\begin{array}{l}\text { Marga Are- } \\
\text { nosa LL2 }\end{array}$ \\
\hline $\begin{array}{c}\text { Sedimentos Bio-Silici- } \\
\text { cláticos }(\text { Carbonato }= \\
50 \% \text { a } 70 \%)\end{array}$ & $\begin{array}{l}\text { Cascalho Bio-Si- } \\
\text { liciclástico CB1 }\end{array}$ & $\begin{array}{c}\text { Areia Bio-Siliciclástica } \\
\text { com Grânulos e Casca- } \\
\text { lhos AB1a }\end{array}$ & $\begin{array}{l}\text { Areia Bio-Sili- } \\
\text { ciclástica AB1b }\end{array}$ & $\begin{array}{l}\text { Marga Calcá- } \\
\text { rea LB1 }\end{array}$ \\
\hline $\begin{array}{c}\text { Sedimentos Bioclás- } \\
\text { ticos (Carbonatos }> \\
70 \%)\end{array}$ & $\begin{array}{l}\text { Cascalho Bio- } \\
\text { clástico CB2 }\end{array}$ & $\begin{array}{c}\text { Areia Bioclástica com } \\
\text { Grânulos e Cascalhos } \\
\text { AB2a }\end{array}$ & $\begin{array}{l}\text { Areia Bioclásti- } \\
\text { ca } \mathrm{AB} 2 \mathrm{~b}\end{array}$ & $\begin{array}{l}\text { Lama Calcá- } \\
\text { ream LB2 }\end{array}$ \\
\hline
\end{tabular}

Fonte: Modificada de Vital et al. (2006).

constituída por sedimentos de granulometria silte, com os grãos variando de muito pobremente a pobremente selecionados. Por outro lado, os teores de carbonato e matéria orgânica são mais elevados se comparados a Lama Terrígena, variam de 33 a $40 \%$ e de 2 a $23 \%$, respectivamente. Ambas as fácies são interpretadas como subfácies de Planície de Intermaré (Intertidal
Flat) (SILVA, 1991) devido à presença de conchas e raízes em estado de decomposição (Tabela_2).

Observa-se nos testemunhos as intercalações entre fácies lamosas, indicadoras de Planícies de Intermaré, com fácies arenosas, que definem os Canais de Maré, o que comprova a intensa dinâmica costeira a qual a região está submetida.

Tabela 2: Características distintivas e descrição das fácies identificadas nesse estudo.

\begin{tabular}{|c|c|c|c|c|}
\hline $\begin{array}{c}\text { Fácies } \\
\text { Caract. } \\
\text { Distintivas }\end{array}$ & $\begin{array}{c}\text { Areia } \\
\text { Siliciclástica } \\
\text { com Grânulos e } \\
\text { Cascalhos AS1a }\end{array}$ & $\begin{array}{c}\text { Areia Siliciclástica } \\
\text { AS1b }\end{array}$ & $\begin{array}{l}\text { Lama Terrígena } \\
\text { LL1 }\end{array}$ & Marga Arenosa LL2 \\
\hline Granulometria & Média a Grossa & Muito Fina a Média & Silte & Silte \\
\hline Grau de Seleção & $\begin{array}{c}\text { Moderadamente } \\
\text { a Pobremente } \\
\text { Selecionado } \\
\end{array}$ & $\begin{array}{c}\text { Moderadamente } \\
\text { a Pobremente } \\
\text { Selecionado }\end{array}$ & $\begin{array}{l}\text { Muito Pobremente } \\
\text { a Pobremente } \\
\text { Selecionado }\end{array}$ & $\begin{array}{l}\text { Muito Pobremente } \\
\text { a Pobremente } \\
\text { Selecionado }\end{array}$ \\
\hline Arredondamento & $\begin{array}{c}\text { Anguloso a } \\
\text { Subarredondado }\end{array}$ & $\begin{array}{l}\text { Subanguloso a } \\
\text { Arredondado }\end{array}$ & - & - \\
\hline $\begin{array}{c}\text { Teor de } \\
\text { Carbonato }(\%)\end{array}$ & 3 a 22 & 0 a 15 & 2 a 29 & 33 a 40 \\
\hline $\begin{array}{c}\text { Teor de Matéria } \\
\text { Orgânica }(\%)\end{array}$ & 0 a 3 & 0 a 4 & 1 a 14 & 2 a 23 \\
\hline Subfácies & Canais de Maré & Canais de Maré & $\begin{array}{l}\text { Planície de } \\
\text { Intermaré }\end{array}$ & $\begin{array}{l}\text { Planície de } \\
\text { Intermaré }\end{array}$ \\
\hline
\end{tabular}


Processamento Digital das Imagens Radiográficas dos Testemunhos Vibracorer

O processamento digital das imagens radiográficas permitiu realçar as variações granulométricas e estruturas sedimentares dos testemunhos do vibracorer, destacando as intercalações das fácies lamosas e arenosas (Figura_2). As composições coloridas também auxiliaram na identificação dos bioclastos presentes nos sedimentos coletados. Trata-se, em sua maioria, de bivalves, mas ocorrendo também gastrópodes e detritos de conchas, esponjas e algas calcárias, realçados em tonalidades esbranquiçadas devido ao comportamento espectral dos carbonatos.

Nas fácies lamosas (Lama Terrígena e Marga Arenosa) a granulometria é visivelmente mais fina, as radiografias processadas demonstraram textura lisa para estes fáceis em resposta ao comportamento espectral para os sedimentos mais úmidos, apresentando-se em tons escuros. Entretanto, nas frações com maior concentração de carbonato (conchas), a coloração é mais esbranquiçada. Ainda para a Lama Terrígena e a Marga
Arenosa observa-se a alternância cíclica de lâminas de granulometria argila, em tons escuros, e silte, em tons mais claros. Esta diferença de tonalidade também reflete a resposta espectral da matéria orgânica que exibe tons mais escuros nas lâminas que apresentam maior concentração. Assim foi possível realçar as laminações plano-paralelas que caracterizam o ambiente de baixa energia da Planície de Intermaré (Figura_2).

Enquanto para as fácies arenosas (Areia Siliciclástica com Grânulos e Cascalhos e Areia Siliciclástica), a granulometria é claramente mais grossa, após os processamentos, os negativos das radiografias apresentaram textura mais rugosa para estas fáceis em virtude dos sedimentos serem menos úmidos, e logicamente de maior granulometria variando de areia fina a grossa, marcadas por tons claros. A tonalidade mais clara está relacionada à resposta espectral para os espaços vazios, devido a maior porosidade associada à maior granulometria e a um arranjo pobremente selecionado. Igualmente, para o maior teor de carbonato em detrimento da concentração de matéria orgânica que é muito reduzida (Figura_2).
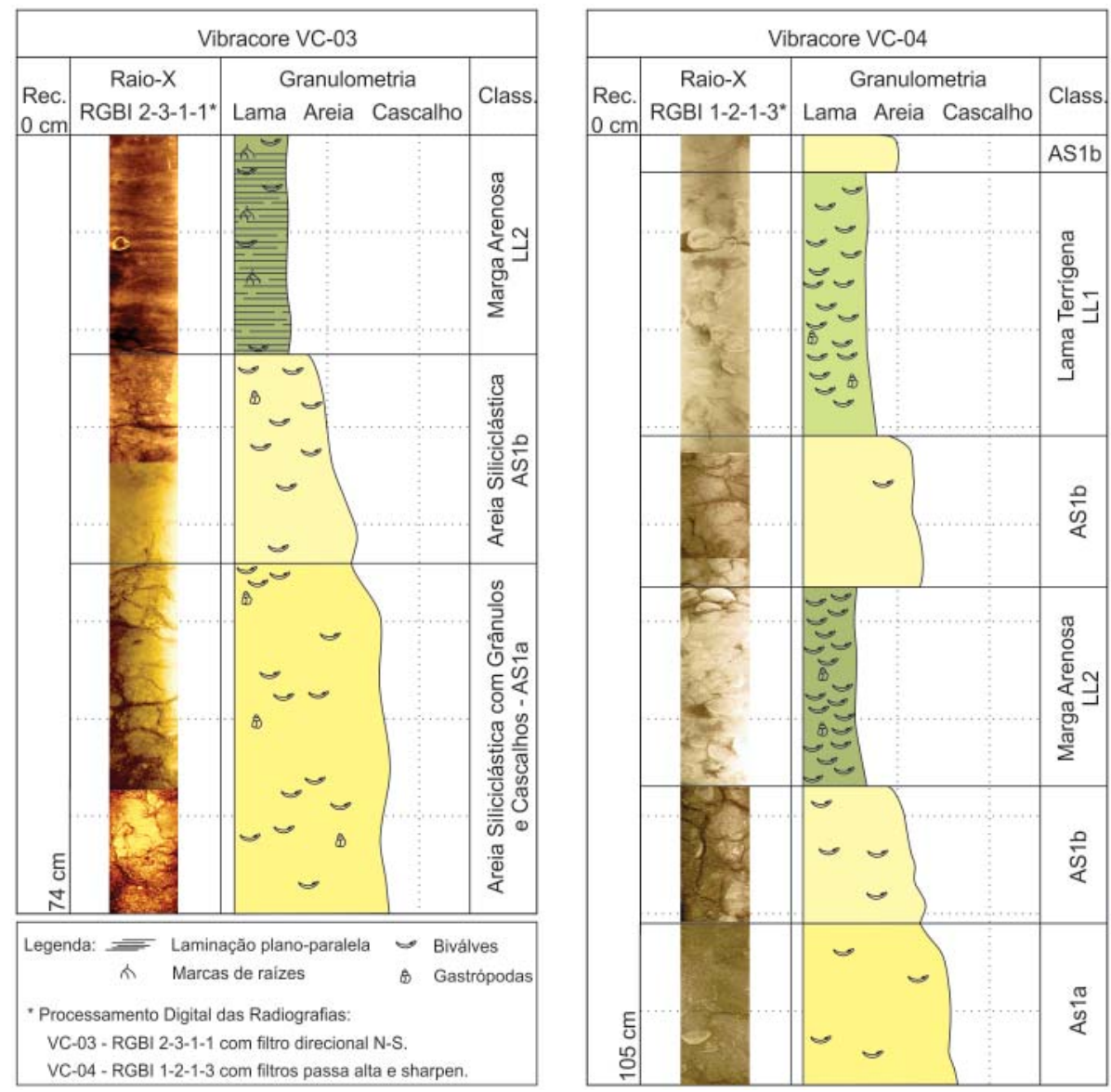

Figura 2 - Colunas (alo)estratigráficas para os vibracores VC-03 e VC-04, integradas ao processamento digital das respectivas imagens radiográficas. 


\section{Processamento Digital das Imagens de Satélites}

\section{Identificação das feições geológicas e geomorfológicas}

Algumas técnicas de PDI foram utilizadas em imagens recentes do satélite Landsat 8 - OLI para identificação das feições geológicas e geomorfológicas da área. Dentre as quais destaca-se a utilização de três tripletes de composição colorida RGB: o primeiro, composto pela combinação das bandas do visível com composição RGB 4-3-1, na qual foi substituída a banda Azul pela Costeira, especial para estudos costeiros; o segundo, formado pela combinação das bandas do infravermelho RGB 7-6-5; e o terceiro, combinando a banda 2 (não utilizada nas composições anteriores), e mixando com uma banda do infravermelho próximo e outra do distante RGB 2-5-7, procurando utilizar desta forma o maior número de informações possíveis na composição da imagem (Figura_3).

A composição colorida RGB 4-3-1 corresponde ao triplete de bandas com comprimentos de onda situados no visível associadas a banda 1, que aproximou as cores ao observado no "mundo real" pela visão humana, realçando as feições costeiras.

A segunda composição colorida utilizada foi a RGB 7-6-5, na qual os comprimentos de onda das bandas não fazem parte do visível, sendo a composição colorida por elas formada chamada de falsa cor. Neste caso, foram realçados os Depósitos Eólicos e de Praia e os Depósitos Eólicos Vegetados em coloração esbranquiçada, devido à alta reflectância do solo exposto no infravermelho, a banda 6 (infravermelho médio) no canal verde, e a banda 7 (infravermelho distante) no canal vermelho, contrastante com as áreas úmidas, relacionadas aos Depósitos de Supramaré e Manguezal, em tonalidade azul escuro devido a banda 5 (infravermelho próximo) no canal do azul, banda de reflectância nula para a água, que destacou os evaporadores de salinas e tanques de carcinicultura também com reflectância nula.

Assim como na composição anterior obteve-se uma falsa cor para este último triplete de composição RGB 2-5-7, na qual as áreas lamosas (Depósitos de Supramaré e Manguezal) foram realçadas em cor verde vibrante devido a banda 5 (infravermelho próximo) no canal verde, resultando também em ausência de cores para a água pois na banda utilizada a água tem reflectância nula. Os Depósitos Eólicos e de Praia e os Depósitos Eólicos Vegetados, bem como dunas e solo exposto, foram evidenciados em cores claras (com muito brilho) em virtude da reflectância relativamente elevada em todos os canais.

Cada triplete foi convertido individualmente para Hue e utilizados para a composição híbrida HRGBI 257-765-431-8. O Hue $(\mathrm{H})$, ou matiz, define a cor espectral dominante, ou seja, a imagem Hue derivada de três bandas é livre de sombra, porque os valores dos pixels são independentes de iluminação e estão apenas relacionados às assinaturas de reflectância das três bandas. Desta forma, o Hue 2-5-7 no canal do vermelho, realça as ilhas barreiras, os campos de dunas e as feições de solo exposto. Já o Hue 7-6-5 inserido no canal do verde ressalta as áreas lamosas em tonalidades verdes. Enquanto o Hue 4-3-1 no canal do azul distribui a composição do espectro visível com uma escala azul que varia de claro a escuro. A conversão dos tripletes RGB para o sistema HRGB resultou em tonalidades de cores vibrantes, sendo conveniente a aplicação do filtro passa alta do tipo laplaciano de dimensão $5 \times 5$ ao canal do Intensity (I) com a banda pancromática, que devolve de forma homogênea o contraste da imagem que melhor singulariza as feições costeiras (Figura_3).

Ainda é importante destacar que durante as etapas da criação do mapa geológico e geomorfológico (Figura_1) as composições HSI 4-5-PC1 com filtro passa baixa de médias de dimensão $3 \times 3$ aplicado à $\mathrm{PC} 1$, e RGBI 421-756-317-8, com filtro passa alta do tipo laplaciano de dimensão $5 \times 5$ aplicado à banda pancromática ao canal do Intensity (I), foram utilizadas para confirmação das feições mais sutis.

\section{Análise dos lineamentos morfoestruturais}

A interpretação dos lineamentos morfoestruturais foi centrada na associação entre feições negativas e positivas do relevo, marcadoras dos lineamentos estruturais como, por exemplo, o padrão de drenagens e alinhamento dos segmentos de canais fluviais, e quebras de falésias, sendo estes normalmente considerados excelentes indicadores na identificação dos sítios preferenciais à materialização da deformação neotectônica (AMARO \& STRIEDER, 1994 e FONSECA, 2006).

Diferentes técnicas de PDI foram realizadas com a imagem Landsat 8 - OLI e possibilitaram a identificação dos lineamentos morfoestruturais. Os resultados dos processamentos incluíram filtragem direcional, composição HSI, APC e realce por manipulação dos histogramas. 


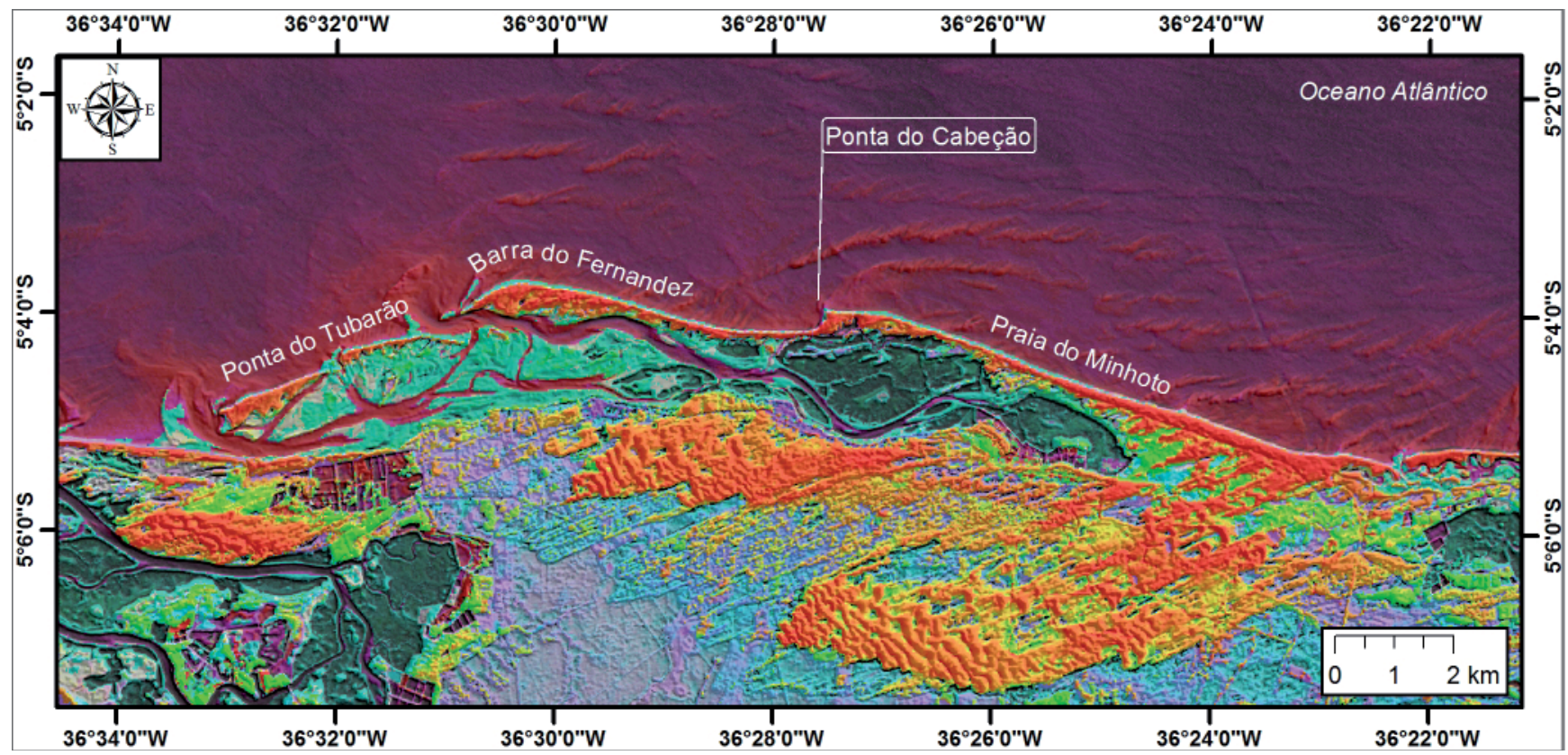

Figura 3 - Composição híbrida HRGBI 257-765-431-8 a partir da combinação de três tripletes de bandas com a aplicação do filtro passa alta do tipo laplaciano de dimensão $5 \times 5$ ao canal do Intensity (I) com a banda pancromática, utilizada para o mapeamento geológicogeomorfológico da área estudada apresentado na Figura_1.

O processo de filtragem direcional foi realizado com filtros passa alta direcionais, utilizados em estudos geológicos de identificação e análise de lineamentos estruturais e topográficos (MATHER, 1999), que foram aplicados na banda 8 (pancromática), possibilitando o realce das feições morfoestruturais, conforme o azimute preferencial. O filtro direcional NE foi o que melhor realçou as feições estruturais paralelas a Falha de Carnaubais, enquanto o filtro NW, melhor destacou os lineamentos paralelos a Falha de Afonso Bezerra (Figura_4).

As técnicas de APC foram usadas para remoção de correlação entre bandas, pois o sombreamento topográfico é a principal causa da existência desta correlação (MATHER, 1999). Sendo assim, a PC1 foi utilizada por conter toda a informação topográfica de sombreamento e luminosidade, o que possibilitou a melhor identificação de lineamentos.

As composições HSI foram essenciais na identificação dos lineamentos estruturais, visto que o sistema utiliza os canais de matiz (Hue), saturação (Saturation) e intensidade (Intensity) de forma independente. O triplete utilizado nas composições foi composto pela combinação da banda 1, utilizada para realçar os lineamentos da província costeira e da plataforma continental, com a PC1 alternadas nos canais $H$ e $S$, e a banda 8 no canal $I$, que devolve de forma homogênea o contraste da imagem, banda na qual foram aplicados os filtros direcionais. Para cada produto, os lineamentos estruturais foram identificados através da análise visual e vetorização. Dentre as composições destacaram-se a HSI 1-PC1-8 com filtro passa alta direcional NE e HSI PC1-1-8 com filtro passal alta direcional NW, como sendo as que mais realçaram os lineamentos morfoestruturais costeiros paralelos às falhas de Carnaubais $\mathrm{e}$ Afonso Bezerra respectivamente (Figura 4).

A caracterização de padrões e anomalias da rede de drenagem, de canais fluviais e canais de maré, aliada à análise das outras feições do relevo, produziu um conjunto de elementos geomórficos usualmente relacionados à atividade neotectônica e permitiu a elaboração do mapa de lineamentos morfoestruturais interpretados para a zona costeira, como auxílio à interpretação da morfologia e geometria das feições costeiras, como faixa de praia, ilhas barreiras, barras arenosas, canais de maré, entre outras, diante do arranjo cinemático da região. No caso do sistema de ilhas barreiras, por exemplo, como mostra a Figura 5, observa-se que as ilhas localizadas a leste do sistema de falhas de Carnaubais e Afonso Bezerra obedecem à orientação da linha de costa e a migração no sentido WSW, acompanhando a direção geral da Falha de Carnaubais. As ilhas barreiras localizadas na porção mediana da calha, ou seja, entre as duas grandes falhas, são estreitas, alongadas e paralelas à linha de costa, enquanto aquelas localizadas na porção oeste obedecem à orientação geral NW da Falha de Afonso Bezerra (NASCIMENTO, 2009). 
Influência Neotectônica na Morfologia do Sistema de Ilhas Barreiras, Nordeste do Brasil

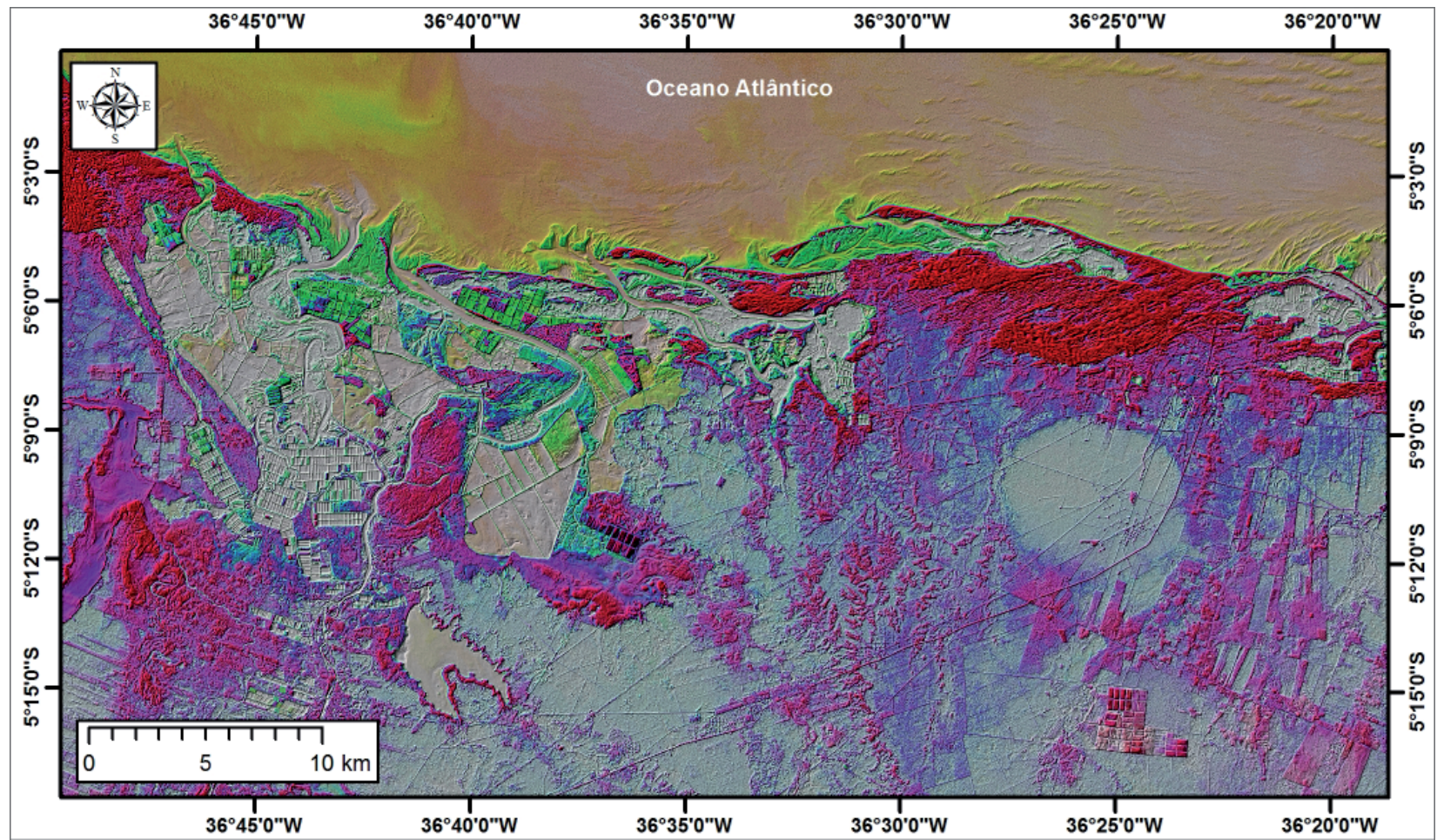

Figura 4 - Imagem HSI 1-PC1-8 com filtro passa alta direcional NE, com a qual foram interpretados os lineamentos morfoestruturais costeiros paralelos a Falha de Carnaubais (NE).

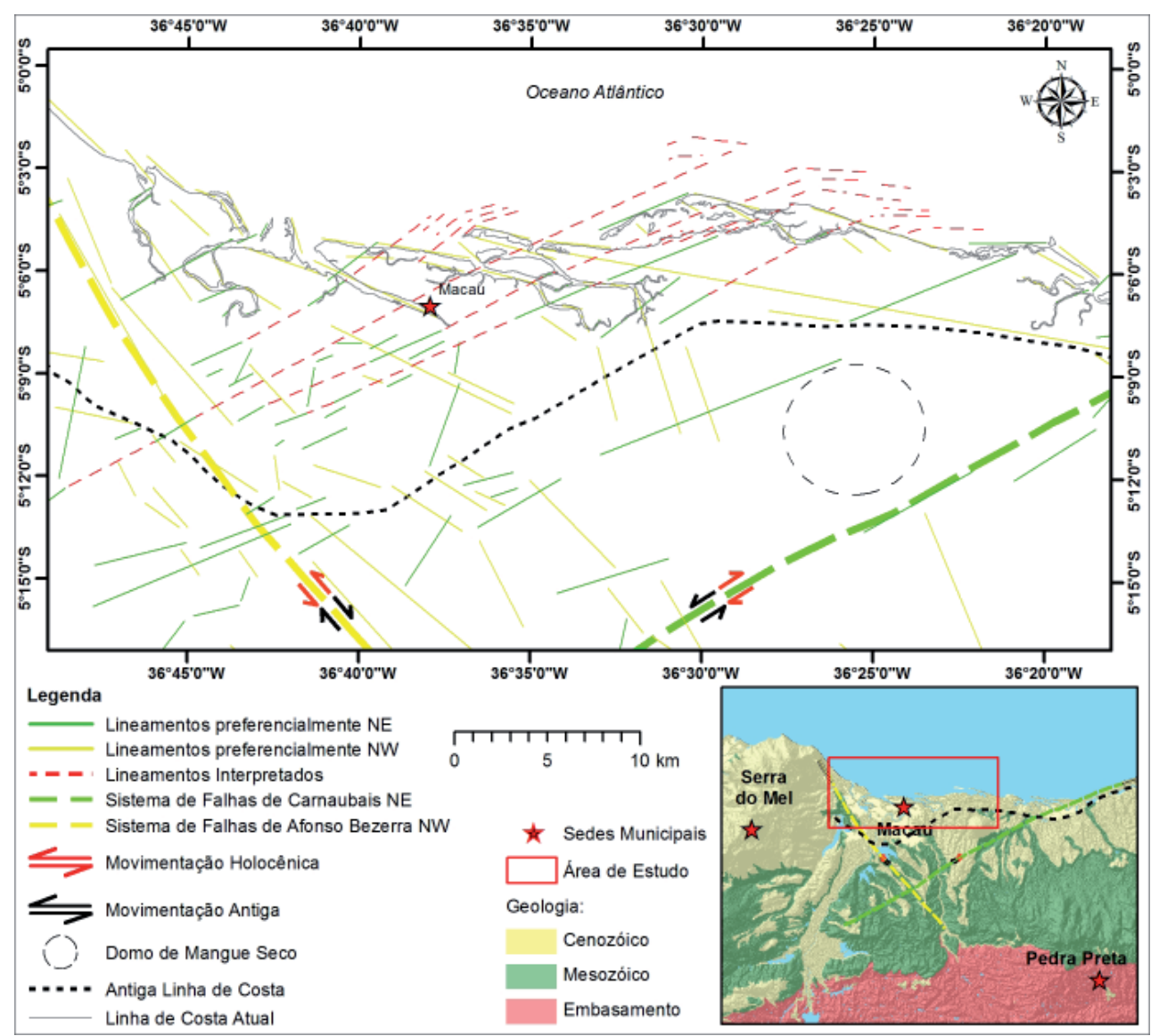

Figura 5 - Mapa dos lineamentos estruturais integrados na zona costeira e na plataforma continental rasa próxima ao sistema de ilhas barreiras, por meio do prolongamento de padrões geométricos de anomalias da rede de drenagens, aliadas aos demais padrões do relevo do litoral, baseado na interpretação visual das imagens HSI 1-PC1-8 com filtro passa alta direcional NE e HSI PC1-1-8 com filtro passa alta direcional NW. 
Os lineamentos identificados na plataforma continental foram extrapolados a partir da província costeira, onde foi possível correlacioná-los com a geometria de segmentos litorâneos. Estes lineamentos interpretados estão relacionados a segmentação dos canais de maré e segmentos de drenagens que obedecem preferencialmente às descontinuidades estruturais. Tal estrutura é evidenciada na região do estuário Diogo Lopes (Figura_6a) e ao norte da cidade de Macau (Figura_6b), onde a formação dos deltas na foz dos rios Casqueira e Conceição ocorre de forma segmentada, com geometria de direção geral preferencial NE, contrária a direção hidrodinâmica deposicional da deriva litorânea E-W. Na mesma região Nascimento (2009) identificou na análise multitemporal de produtos de sensoriamento remoto dos anos de 1954 a 2003 o escalonamento geométrico da linha de costa no interior do estuário, que ocorre intercalado pelos lineamentos morfoestruturais costeiros, subparalelos à Falha de Carnaubais, designando essa feição costeira de Escalonamento Morfológico Tércio-Quaternário (Figura_6c), como reflexo na morfologia costeira de falhas escalonadas, o que constata a influência destes escalonamentos na deposição e geometria dos deltas e estuários.

\section{Discussão}

Os estudos ora efetuados integram o conhecimento acerca dos registros geológicos de subsuperfície com os estudos dos lineamentos morfoestruturais da Província Costeira, visando o entendimento global da atuação dos eventos neotectônicos ao longo do Cenozoico costeiro e correlações com a plataforma continental.

A análise morfotectônica realizada a partir da interpretação de imagens digitais de satélites, associada a integração de mapas prévios (VALENTIM DA SILVA et al., 2010 e PALHANO, 2013), permitiu um esboço do quadro morfodinâmico regional, integrando as informações disponíveis e acrescentando informações inéditas, especialmente em relação a análise dos lineamentos das feições morfoestruturais, que revelaram um conjunto de aspectos compatíveis com a atuação dos eventos neotectônicos. Os resultados alcançados na análise regional foram correlacionados a região circunvizinha, compreendendo a Província Costeira no setor do estuário Diogo Lopes, visando a verificação dos princípios da análise morfotectônica.

A atividade neotectônica foi evidenciada também por Valentim da Silva et al. (2010) através do mapeamento de

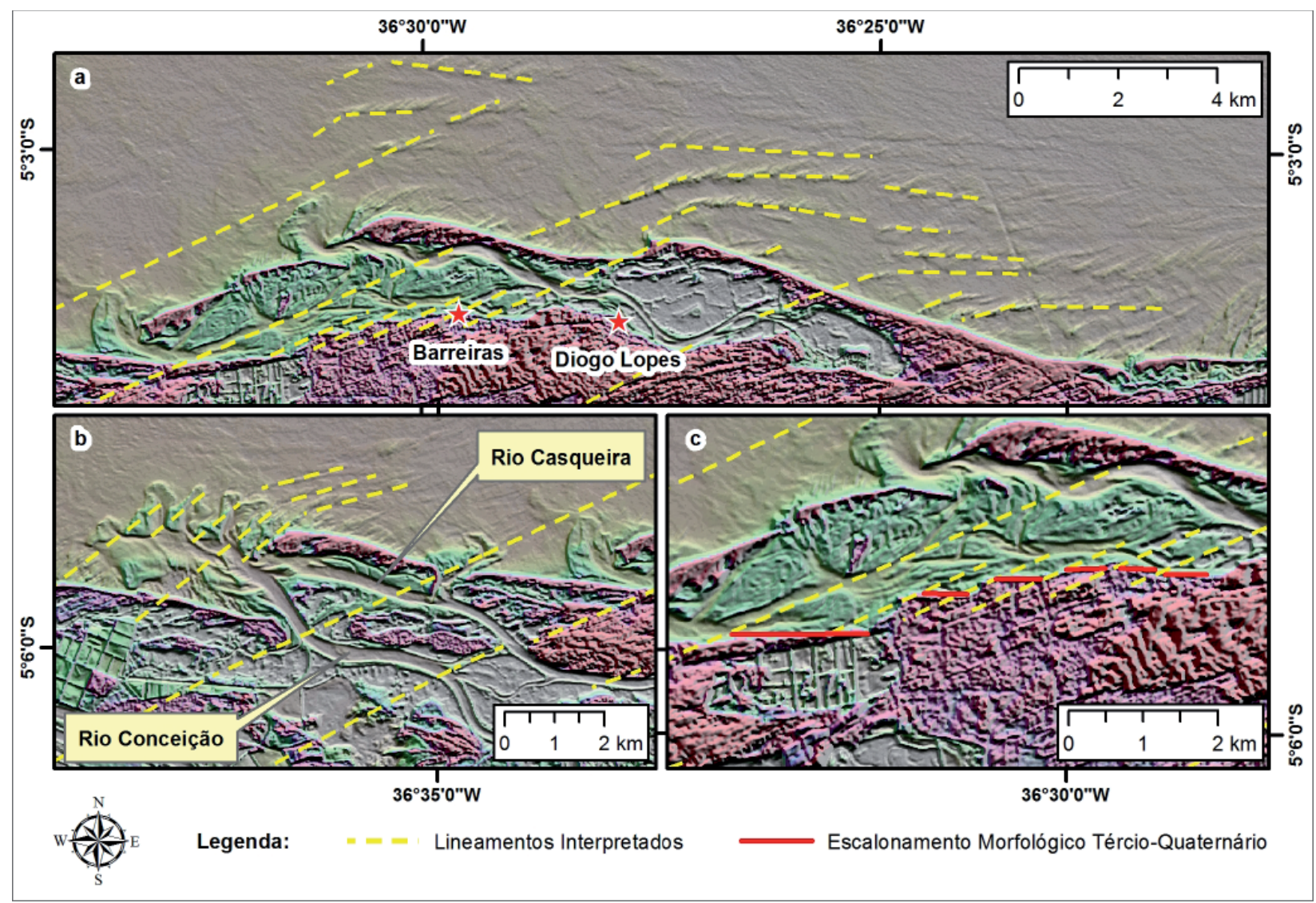

Figura 6 - Lineamentos morfoestruturais interpretados para a zona costeira, baseado na imagem Landsat 8 - OLI de composição HSI 1-PC1-8 com filtro passa alta direcional NE. a) Feições morfoestruturais de fundo submarino próximas ao estuário Diogo Lopes. b) Reflexo de falhas escalonadas na formação do delta dos rios Casqueira e Piranhas. c) Escalonamento Morfológico Tércio-Quaternário. 
lineamentos morfoestruturais obtidos em imagens do satélite China-Brazil Earth Resources Satellite (CBERS 2B) e do Shuttle Radar Topography Mission (SRTM) (FARR et al., 2007), que constataram que os padrões de drenagens, bem como bordas de lagoas, escarpas e encostas, encontram-se paralelos ao par conjugado do sistema de falhas. Utilizando as composições HSI 1-PC1-8 com filtro passa alta direcional NE e HSI PC1-1-8 com filtro passal alta direcional NW em imagens do Landsat 8 - OLI para a identificação dos lineamentos morfoestruturais costeiros, ficou evidente que os lineamentos exercem controle na geometria do litoral e no padrão morfológico do sistema de ilhas barreiras, que possuem uma geometria exclusiva no litoral setentrional do $\mathrm{RN}$, paralelo às falhas de Carnaubais e Afonso Bezerra.

A existência deste sistema de falhas conexo às modificações geomorfológicas é demonstrada ainda por Souto (2009) que identificou uma estruturação com modelo em dominó, a aproximadamente $2,5 \mathrm{~m}$ de profundidade, por meio de discordâncias dos refletores observados no radargrama A-A', localizado a sul da Ilha da Ponta do Tubarão (Figura_7a). Silva (1991) e Nascimento (2009) também identificaram nos perfis esquemáticos de integração de sondagens B-B' (Figura_7b) e C-C' (Figura_7c), blocos escalonados relacionados com meio grábens formados pela acomodação da Falha de Carnaubais com a estruturação similar a estrutura em dominó, sendo parte de uma estruturação maior de grabens e horsts, que corresponderiam à localização das ilhas barreiras do Corta Cachorro, Camapum, Ponta do Tubarão e Barra do Fernandez (Figura_7).

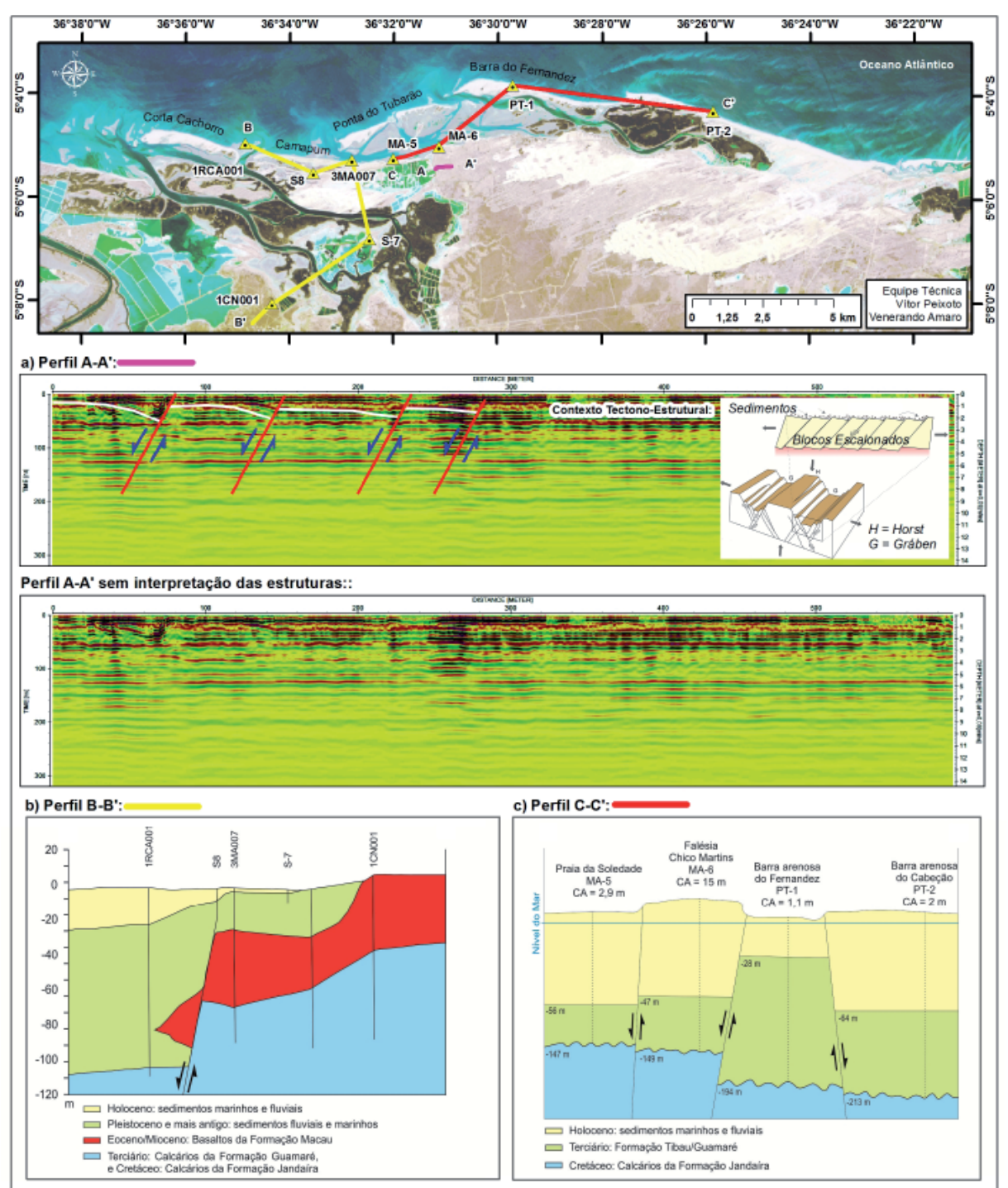

Figura 7 - Perfis esquemáticos que comprovam a movimentação associada à reativação holocênica. a) Perfil A-A': radargrama no qual é possivel evidenciar a estruturação em blocos escalonados em modelo dominó; b) Perfil B-B': integração de sondagens, na porção oeste correspondente às ilhas de Camapum e Corta-Cachorro sob influência de um gráben, e porção leste, nas proximidades na ilha barreira de Ponta do Tubarão sob influência de um horst; c) Perfil C-C': integração de sondagens, demonstrando a estruturação similar ao modelo em dominó, associado com uma estruturação maior de grabens e horsts. Fonte: Modificado de Souto (2009), Silva (1991) e Nascimento (2009). 
O modelo de blocos escalonados similar a estrutura em dominó ainda pode ser evidenciado na plataforma oceânica, defronte ao estuário Diogo Lopes (Localização do estuário na Figura_6a), onde os lineamentos interpretados das feições submersas obedecem a orientação do sistema de falhas existente na região e são paralelos a geometria do litoral. Estas feições morfoestruturais de fundo submarino são similares a bancos arenosos e/ou sandwaves (VITAL et al., 2001), cuja ocorrência está associada aos altos estruturais do modelo em dominó, e cujas cristas ocorrem com geometria preferencial NE, paralela à Falha de Carnaubais.

Os resultados dos testemunhos com vibracorer foram integrados numa base georreferenciada que tornou possível a elaboração de uma seção litofaciológica esquemática da área de estudo em conjunto com vibracores de Santos Neto (2007) e Palhano (2013) que, associada com as sondagens mais profundas, 1PT001 e 1PT002, compiladas por Nascimento (2009), permitiu a correlação entre os depósitos pretéritos e não-aflorantes identificados, com o contexto morfotectônico e de intensa dinâmica ao qual a área está submetida (Figura_8). Apesar da diferença de recuperação entre as sonda- gens e os testemunhos de vibracorer analisados neste trabalho, procurou-se demonstrar quais os reflexos do basculamento evidenciado nas sondagens para o sistema deposicional costeiro holocênico.

De maneira geral, evidenciam-se em todos os testemunhos de vibracorer analisados, intercalações entre fácies lamosas correspondentes à Planície de Intermaré e fácies arenosas, marcadores de Canais de Maré. Estes setores estão caracterizados por sequências deposicionais com granocrescência ascendente e com granodecrescência ascendente, que indicam a migração e reocupação do canal de maré, que comprova a intensa dinâmica costeira a qual a região está submetida, de alta instabilidade das feições morfológicas. Esta instabilidade costeira marcada pelo surgimento e migração dos canais de maré ocorre associada ao controle tectônico do sistema de falhas de Carnaubais (NE), sendo possível correlacionar a geometria do litoral com a direção de abertura dos canais, que se formam sempre paralelos aos lineamentos de direção geral NE. A abertura e o fechamento dos canais de maré ocorrem em curto intervalo de tempo, de anos a décadas e, preferencialmente, em situações geológicas de descontinuidades estruturais

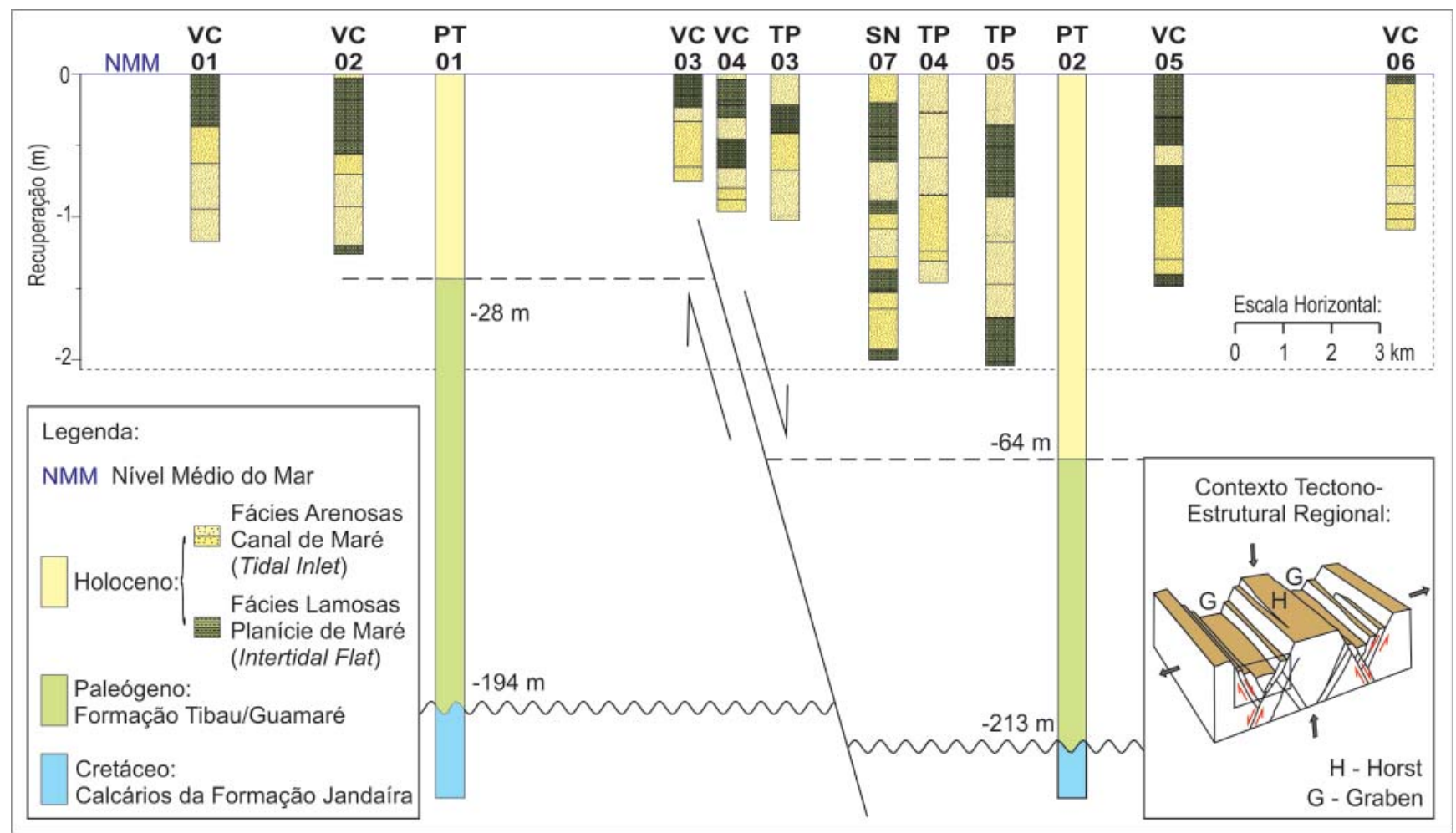

Figura 8 - Seção litofaciológica formada pela integração dos testemunhos de vibracorer, que representam os depósitos holocênicos de subsuperficie, em associação com aqueles das sondagens, localizadas em perfis alinhados, que demonstra a movimentação tectônica do setor, conforme contexto estrutural regional (Ver localização do perfil na Figura1). 
prévias, como atesta a geometria da linha de costa, o escalonamento evidente entre as diferentes profundidades entre as fácies nos testemunhos realizados e a correlação entre os afinamentos das barras/esporões arenosos e os lineamentos estruturais que condicionam trechos de drenagem e falhamentos no continente.

\section{Conclusões}

Os resultados permitiram estabelecer um quadro coerente dos registros costeiros por testemunhagem vibracorer comparados a sondagens com maior profundidade de alcance. As análises sedimentológicas permitiram a caracterização de quatro fácies sedimentares distintas: Areia Siliciclástica com Grânulos e Cascalhos (AS1a), Areia Siliciclástica (AS1b), Lama Terrígena (LL1) e Marga Arenosa (LL2). A interpretação das características sedimentológicas dos testemunhos permitiram identificar ainda subfácies de Planície de Intermaré correlatas às fácies Lama Terrígena (LL1) e Marga Arenosa (LL2), e de Canais de Maré associadas às fácies Areia Siliciclástica (AS1b) e Areia Siliciclástica com Grânulos e Cascalhos (AS1a), assim como sequências deposicionais com granocrescência ascendente, e com granodecrescência ascendente, indicando a migração e reocupação de alguns setores pelos canais de maré.

O emprego de tratamentos digitais de imagens nos produtos radiográficos digitais foi fundamental para realçar as análises granulométricas e ampliar a visão sinóptica na análise sedimentológica dos testemunhos de vibracorer coletados. Nesses, a intercalação das fácies lamosas e arenosas se tornou mais evidente, a partir da diferenciação das texturas e tonalidades: textura lisa e alternância cíclica entre tonalidade escura e clara evidenciando as laminações plano-paralelas entre Lama Terrígena (LL1) e Marga Arenosa (LL2); a textura rugosa e tonalidade clara marcou os níveis de Areia Siliciclástica com Grânulos e Cascalhos e Areia Siliciclástica. Além disso, auxiliou na identificação e posicionamentos dos bioclastos evidenciados com cores esbranquiçadas.

A correlação de perfis geológicos dos testemunhos de vibracorer de subsuperfície com sondagens profundas permitiu observar intercalações entre fácies lamosas, marcadoras de Planície de Intermaré, e fácies arenosas definidoras de Canais de Maré, que comprovaram a intensa dinâmica costeira a qual a região está submetida. Possibilitou, ainda, relacionar os efeitos da neotectônica nas modificações da morfologia costeira, uma vez que é possível observar a influência do controle tectônico do Sistema de Falhas de Carnaubais sobre a geometria do litoral e a direção de surgimento dos canais de maré NE. Sendo assim, foi possível associar a ocorrência dos esporões arenosos e ilhas barreiras às áreas de soerguimento dos blocos estruturais, controlados por sistema de falhamentos profundos, antigos e reativados até o presente. Provavelmente, os locais de abertura dos canais de maré ocorrerão preferencialmente acompanhando a geometria e a movimentação das descontinuidades que marcam os sistemas dos falhamentos que controlam tais blocos em subsidência, com grande influência da direção geral de lineamentos morfoestruturais NE.

Outrossim, a análise morfotectônica através das composições HSI 1-PC1-8 com filtro passa alta direcional NE e HSI PC1-1-8 com filtro passal alta direcional NW permitiu comprovar a influência da reativação tectônica do Sistema de Falhas de Carnaubais na geometria do estuário Diogo Lopes, associado a um sistema de blocos escalonados. Os lineamentos identificados na plataforma continental foram extrapolados a partir da província costeira, onde foi possível correlacioná-los com a geometria de segmentos litorâneos. Estes lineamentos interpretados estão relacionados a segmentação dos canais de maré e segmentos de drenagens que obedecem preferencialmente às descontinuidades estruturais. Assim, o controle morfotectônico se agrega aos processos deposicionais e erosivos na abertura e fechamento de canais de maré ao longo da faixa de praia e do sistema de ilhas barreiras.

\section{Agradecimentos}

Os autores agradecem o suporte financeiro da REDE 05 - PETROMAR (CTPETRO-FINEP/PETROBRAS/CNPq), por meio dos Projetos Cooperativos MOLECO e CRONALOG, da Agência Nacional do Petróleo, Gás Natural e Biocombustíveis - ANP, da Financiadora de Estudos e Projetos - FINEP e do Ministério da Ciência, Tecnologia e Inovação - MCTI por meio do Programa de Recursos Humanos da ANP para o Setor Petróleo e Gás - PRH43-ANP/MCTI. Ao apoio técnico e operacional das equipes do Laboratório de Geoprocessamento (GEOPRO) do Departamento de Geologia da Universidade Federal do Rio Grande do Norte (GEOPRO/DGEO/UFRN e ao Programa de Pós-graduação em Ciência e Engenharia do Petróleo da UFRN (PPGCEP/UFRN). 


\section{Referências Bibliográficas}

AMARO, V.E.; LIMA, F.G.F.; SANTOS, M.S.T. An evaluation of digital elevation models to short-term monitoring of a high energy barrier island, northeast Brazil. World Academy of Science, v. 76, p. 317-324, 2013.

AMARO, V.E.; STRIEDER, A.J. Análise de fotolineamentos e padrões estruturais em imagens de satélite. In: CONGRESSO BRASILEIRO DE GEOLOGIA, 37, 1994, Camburiú. Anais..., p. 443-444, 1994.

BEZERRA, F.H.R. Intraplate paleoseismicity in northeastern Brazil. In: NATIONAL SYMPOSIUM ON TECTONIC STUDIES AND INTERNATIONAL SYMPOSIUM ON TECTONICS, 7, 1999, Lençóis. Anais..., p. 12-16, 1999.

BEZERRA, F.H.R.; BRITO NEVES, B.B.; CORRÊA, A.C.B.; BARRETO, A.M.F.; SUGUIO, K. Late Pleistocene tectonicgeomorphological development within a passive margin - the Cariatá trough, northeastern Brazil. Geomorphology, v. 97, p. 555-582, 2008.

BEZERRA, F.H.R. Deformação tectônica na Formação Barreiras: exemplos das bacias Potiguar e Paraíba, Brasil. In: CONGRESSO DA ASSOCIAÇÃO BRASILEIRA DE ESTUDOS DO QUATERNÁRIO, 13, 2011, Anais... Disponível em: <http://www.abequa.org.br/trabalhos/Bezerra_FHR_Simposio_Barreiras.pdf $>$. Acessado em: 20/05/2015.

BONOW, J.M.; LIDMAR-BERGSTRÖM, K.; JAPSEN, P. Palaeosurfaces in central West Greenland as reference for identification of tectonic movements and estimation of erosion. Journal of Global and Planetary Change, v. 50, p. 161-183, 2006.

DANTAS, E.P. Gravimetria e sensoriamento remoto: uma aplicação ao estudo da tectônica recente entre Macau e São Bento do Norte (RN). (Dissertação de Mestrado em Geodinâmica e Geofísica), Universidade Federal do Rio Grande do Norte, Natal, 101p. 1998.

DANTAS, R.R.S.; LIMA NETO, H.C.; FERREIRA, J.M.; DO NASCIMENTO, A.F.; ASSUMPCAO, M.; BEZERRA, F.H.R.; MENEZES, E.A.S.; SPINELI, R.M.P.; COSTA, N.P. Atividade sísmica em Pedra Preta - RN em 2010. In: INTERNATIONAL CONGRESS OF THE BRAZILIAN GEOPHYSICAL SOCIETY, 12, 2011, Rio de Janeiro, Anais..., p. 3191, 2011.

DIAS, G.T.M. Classificação de sedimentos marinhos proposta de representação em cartas sedimentológicas. In: CONGRESSO BRASILEIRO DE GEOLOGIA, 39, Salvador, Anais..., p. 423426, 1996.
FARIAS, P.R.C. Geologia de Superfície da Área de MacauRN. (Relatório Final Petrobrás), GEXP, GELAB, 76 p., 1997.

FARR, T.G.; ROSEN, P.A.; CARO, E.; CRIPPEN, R.; DUREN, R.; HENSLEY, S.; KOBRICK, M.; PALLER, M.; RODRIGUEZ, E.; ROTH, L.; SEAL, D.; SHAFFER, S.; SHIMADA, J.; UMLAND, J.; WERNER, M.; OSKIN, M.; BURBANK, D.; ALSDORF, D. The Shuttle Radar Topography Mission. Review of Geophysics, v.45, DOI:10.1029/2005RG000183. RG2004.. 2007.

FERREIRA, A.T.S.; AMARO, V.E.; SANTOS, M.S.T. Geodésia aplicada na integração de dados topográficos e batimétricos na caracterização de superfícies de praia. Revista Brasileira de Cartografia, v. 66, p. 167-184, 2014.

FREIRE, G.S.S.; CAVALCANTI, V.M.M.; MAIA, L.P.; LIMA, S.F. Classificação dos sedimentos da plataforma continental do Estado do Ceará. In: SIMPÓSIO DE GEOLOGIA DO NORDESTE, Anais..., p. 209-211, 1997.

FOLK, R.L. The distinction between grain size and mineral composition in sedimentary rock nomenclature. Journal of Geology, v. 62, n. 4 p. 344-359, 1954.

FOLK, R.L.; WARD, W. Brazos river bar: a study in the significance of grain size parameters. Journal of Sedimentary Research Petrology, v. 27 p. 3-26, 1957.

FONSECA, V.P. Estudos morfotectônicos na área do baixocurso do Rio Açu (Açu-Macau), Rio Grande do Norte. (Dissertação de Mestrado em Geociências), Universidade Federal de Minas Gerais, Belo Horizonte, 103 p., 1996.

FONSECA, V.P. Estudos morfotectônicos aplicados à planície costeira do Rio Grande do Sul. (Tese de Doutoramento em Geociências), Universidade Federal do Rio Grande do Sul, Porto Alegre, 307p., 2006.

FUCHS, K.; MULLER, B. World stress map of the Earth: a key to tectonic processes and technological applications. Naturwissenschaften, Berlin, v. 88, p. 357-371, 2001.

JAPSEN, P.; BONOW, J.M.; GREEN, P.F.; CHALMERS, J.A.; LIDMAR-BERGSTRÖM, K. Elevated, passive continental margins: long-term highs or Neogene uplifts? New evidence from West Greenland. Earth and Planetary Science Letters, v. 248 , p. $330-339,2006$.

LARSONNEUR, C. La cartographie des depot meubles sur le plateau continental francais: methode mise au point et utilisee en manche. Journal of Research Oceanography, v. 2, p. 3439, 1977.

LIMA, C.C. Expressions topographiques et structurales de 
l'etat de compression generalisee au sein de la plaque sudaméricaine. (Tese de Doutoramento em Géosciences), Ecole de Physique et Matériaux, Université Rennes, Rennes, 370 p., 1999.

LIMA, Z.M.C.; VITAL, H.; XAVIER NETO, P.; MEDEIROS, W.E.; ANDRADE, P.R.O. Sand spit from northeast Brazil: Highresolution Quaternary analogs for reservoir models. In: AAPG ANNUAL MEETING, Houston, Anais..., v. 11, p.A103-A104, 2002.

LISKER, F. Review of fission track studies in northern Victoria Land, Antarctica passive margin evolution versus uplift of the Transantartic Mountains. Journal of Tectonophysics, v. 349, p. 57-73, 2002. Disponível em: <http://ac.els-cdn. com.ez18.periodicos.capes.gov.br/S004019510200046X/1s2.0-S004019510200046X-main.pdf?_tid=e04b36520258-11e5-905e-00000aab0f02\&acdnat $=1432501824$ fed66c8dd3fd3c21b1d1b04602fdb3ef>. Acessado em: $20 / 05 / 2015$.

MATHER, P.M. Computer processing of remotely - sensed images: an introduction. Chichester: John Wiley \& Sons, 1999. $292 \mathrm{p}$.

MOURA-LIMA, E.N.; SOUSA, M.O.L.; BEZERRA, F.H.R.; AQUINO, M.R.; VIEIRA, M. M.; LIMA-FILHO, F.P.; FONSECA, V.P.; AMARAL, R.F. Sedimentação e deformação tectônica cenozóica na porção central da Bacia Potiguar. Revista do Instituto de Geociências, v. 10, n. 1, p. 15-28, 2010.

NASCIMENTO, M.C. A erosão costeira e sua influência sobre a atividade petrolífera: Alternativas sustentáveis na mitigação de impactos ambientais. (Dissertação de Mestrado em Geodinâmica e Geofísica), Universidade Federal do Rio Grande do Norte, Natal, 222 p., 2009.

PALHANO, L.C. Caracterização sedimentológica do sistema de paleoilhas barreiras no Estuário Barreiras/Diogo Lopes, litoral setentrional do RN, através de métodos de testemunhagem por vibração (Vibracorer). (Relatório de Graduação em Geologia), Universidade Federal do Rio Grande do Norte, Natal, 2013.

RIIS, F. Quantification of Cenozoic vertical movements of Scandinavia by correlation of morphological surfaces with offshore data. Global and Planetary Change, v. 12, p. 331357, 1996.

RIOS, V.P.L.; AMARO, V.E. Caracterização dos depósitos sedimentares holocênicos no sistema de ilhas barreiras do Estuário Diogo Lopes, Litoral Setentrional do Rio Grande do Norte. Revista de Geologia, Fortaleza, v. 25, p. 28-45, 2012.

RODRIGUES, S.W.P. Detecção de mudança e sedimentação no estuário do rio Coreaú. (Tese de Doutoramento em Geologia e Geoquímica), Universidade Federal do Pará, Belém, 106 p., 2014.

SANTOS, A.L.S.; AMARO, V.E.; SANTOS, M.S.T. Geodésia de precisão aplicada à análise da evolução morfodinâmica de curto prazo na Ilha Barreira do Corta Cachorro, litoral do Rio Grande do Norte, Nordeste do Brasil. Revista Brasileira de Geomorfologia, v. 15 p. 425-442, 2014.

SANTOS, J. Landsat-8: Download de imagens através dos sites Earth Explorer e GLOVIS. Processamento Digital Geotecnologias e Software Livre. 2013. Disponível em: $<$ http://www.processamentodigital.com.br/wp-content/ uploads/2013/08/20130531_Landsat8_download_USGS.pdf $>$. Acessado em: 20/05/2015.

SANTOS, M.S.T.; AMARO, V.E. Dinâmica sazonal de processos costeiros e estuarinos em sistema de praias arenosas e ilhas barreira no Nordeste do Brasil. Revista Brasileira de Geomorfologia, v. 14, p. 151-162, 2013.

SANTOS, M.S.T.; AMARO, V.E. Rede geodésica para o monitoramento costeiro do litoral setentrional do Estado do Rio Grande do Norte. Boletim de Ciências Geodésicas, v. 17, n. 4, p. 571-585, 2011.

SANTOS NETO, F. Caracterização Morfosedimentar da Ponta do Tubarão. (Relatório de Graduação em Geologia), Universidade Federal do Rio Grande do Norte. Natal, 97 p., 2007.

SHEPARD, F.P. Nomenclature based on sand-silt-clay ratios. Journal of Sedimentology Petrology, v. 24, n. 3, p. 151-158, 1954.

SILVA, C.G. Holocene stratigragraphy and evolution of the Açu River Delta, Rio Grande do Norte State, Northeastern Brazil. (Tese de Doutoramento em Geologia), Duke University, United States, 359 p., 1991.

SILVA, R.L.; NOGUEIRA, A.M.B. Estratigrafia da porção emersa da costa do Rio Grande do Norte. In: SIMPÓSIO SOBRE PROCESSOS SEDIMENTARES E PROBLEMAS AMBIENTAIS NA ZONA COSTEIRA DO NORDESTE DO BRASIL, Recife, Anais..., 1., p. 144-147, 1995.

SOUTO, M. V. S. Análise da Evolução Costeira do Litoral Setentrional do Estado do Rio Grande do Norte, Região Sob Influência da Indústria Petrolífera. (Tese de Doutoramento em Geodinâmica e Geofísica), Universidade Federal do Rio Grande do Norte, Brasil, 177 p., 2009.

SRIVASTAVA, N.K.; CORSINO S.R. Os carbonatos de Touros: Petrografia e Estratigrafia. In: SIMPÓSIO DE GEOLOGIA DO 
NORDESTE, 11, Atas..., p. 165-176, 1984.

STATTEGGER, T.K.; CALDAS, L.H.O.; VITAL, H. Holocene Coastal Evolution of the Northern Rio Grande do Norte Coast, NE, Brazil. Journal of Coastal Research, v. 39, p. 150-155, 2006.

UDDEN, J.A. Mechanical composition of clastic sediments. Geological Society of America Bulletin, v. 25, p. 655-744, 1914.

USGS. United States Geological Survey Earth Explorer. Disponível em: <http://landsat.usgs.gov/band_designations_ landsat_satellites.php $>$ Acesso em 20/01/2015.

USGS. United States Geological Survey Earth Explorer. Disponível em: <http://earthexplorer.usgs.gov> Acesso em 20/01/2015.

VALENTIM DA SILVA, D.R.; AMARO, V.E.; SOUTO, M.V.S.; NASCIMENTO, M.C.; BARROS PEREIRA, B.R.B. Geomorfologia de uma área com alta sensibilidade ambiental na Bacia Potiguar (NE do Brasil). Revista da Gestão Costeira
Integrada, v. 10, n. 4, p. 545-566, 2010

VITAL, H.; TABOSA, W.F.; STATTEGGER, K.; CALDAS, L. Tectonics and bottom morphology control on sediment distribution in the Brazilian northeastern continental margin: São Bento do Norte / Caiçara do Norte Area. In: CHAPMAN CONFERENCE ON THE FORMATION OF SEDIMENTARY STRATA On CONTINENTAl MARGINS, Anais..., Ponce, Puerto Rico, p. 37, 2001.

VITAL, H.; LIMA, Z.M.C., SILVEIRA, I.M.; AMARO, V.E.; SOUTO, M.V.S. Barrier-spit system from the northern Rio Grande do Norte State Coast, NE Brazil: A tectonic control?. In: LATINAMERICAN SEDIMENTOLOGY CONGRESS, 3, Anais..., p. 313-315, 2003.

VITAL, H.; AMARO, V.E.; SILVEIRA, I.M. Coastal erosion on the Rio Grande do Norte State (Northeastern Brazil): Causes and factor versus effects associated processes. Journal of Coastal Research, v. 39, p. 1307-1310, 2006.

WENTWORTH, C.K. A scale of grade and class terms for clastic sediments. Journal of Geology, v. 30, p. 377-392, 1922. 